\title{
Experimental Study on Crack Extension Rules of Hydraulic Fracturing Based on Simulated Coal Seam Roof and Floor
}

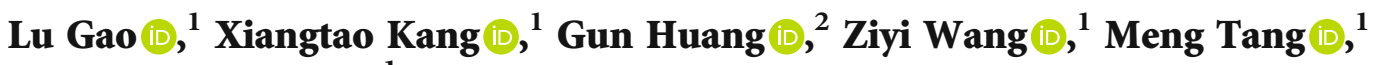 \\ and Xiaoying Shen $\mathbb{D}^{1}$ \\ ${ }^{1}$ Mining College, Guizhou University, Guiyang 550025, China \\ ${ }^{2}$ School of Resources and Safety Engineering, Chongqing University, Chongqing 400044, China \\ Correspondence should be addressed to Xiangtao Kang; xiaokangedu@163.com
}

Received 26 July 2021; Revised 10 September 2021; Accepted 29 November 2021; Published 4 January 2022

Academic Editor: Xin Liang

Copyright @ $2022 \mathrm{Lu}$ Gao et al. This is an open access article distributed under the Creative Commons Attribution License, which permits unrestricted use, distribution, and reproduction in any medium, provided the original work is properly cited.

\begin{abstract}
Hydraulic fracturing can increase the fracture of coal seams, improve the permeability in the coal seam, and reduce the risk of coal and gas outburst. Most of the existing experimental specimens are homogeneous, and the influence of the roof and floor on hydraulic fracture expansion is not considered. Therefore, the hydraulic fracturing test of the simulated combination of the coal seam and the roof and floor under different stress conditions was carried out using the self-developed true triaxial coal mine dynamic disaster large-scale simulation test rig. The results show that (1) under the condition of triaxial unequal pressure, the hydraulic fractures are vertical in the coal seam, and the extension direction of hydraulic fractures in the coal seam will be deflected, with the increase of the ratio of the horizontal maximum principal stress to the horizontal minimum principal stress. The angle between the extension direction of the hydraulic fracture and the horizontal maximum principal stress decreases. (2) Under the condition of triaxial equal confining pressure, the extension of hydraulic fractures in the coal seam are random, and the hydraulic fracture will expand along the dominant fracture surface and form a unilateral expansion fracture when a crack is formed. (3) When the pressure in one direction is unloaded under the condition of the triaxial unequal pressure, the hydraulic fractures in the coal seam will reorientate, and the cracks will expand in the direction of the decreased confining pressure, forming almost mutually perpendicular turning cracks.
\end{abstract}

\section{Introduction}

China is poor in oil and gas but abundant in coal resources. Coal accounts for $94.0 \%$ of the explored reserves of primary energy and always plays an important position in China's energy production [1]. The permeability of coal seam in China is generally in the range of $0.1 \sim 0.001 \times 10^{-3} \mu \mathrm{m}$ [2]. It is difficult to realize gas control due to low permeability and the extraction concentration of gas [3-7], which seriously threatens the safety production of mines. In order to effectively extract the gas in the coal seam, it is necessary to improve the permeability of the coal seam characterized by rich gas and low permeability [8-11]. As an effective method of improving the permeability of the coal seam, hydraulic fracturing has been applied many mines.
The fracture drilling is usually made in the coal seam to conduct fracturing for the whole coal seam during underground hydraulic fracturing. Since Hubbert and Willis [12] put forward the first mechanical theory of hydraulic fracturing. Fan et al. [13] found that the hydraulic fracture initiation and propagation was controlled by the in situ stress. Dong et al. [14] qualitatively described the relationship between hydraulic fracturing, effective stress, and seepage. Cipolla et al. $[15,16]$ established their respective mathematical models for determining the generation of complex fractures to understand the mechanism of fracture propagation. Yang et al. [17] carried out different tests under uniaxial and biaxial compression conditions; the crack propagation processes under different loading conditions were analyzed in the data. Li et al. [18] and Huang et al. [19] observed the 


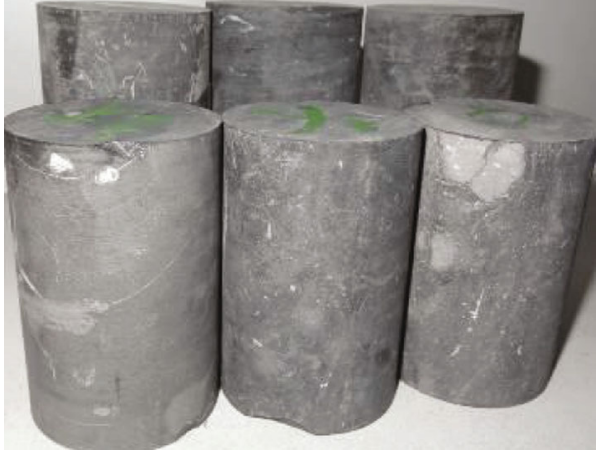

(a) Roof and floor specimens

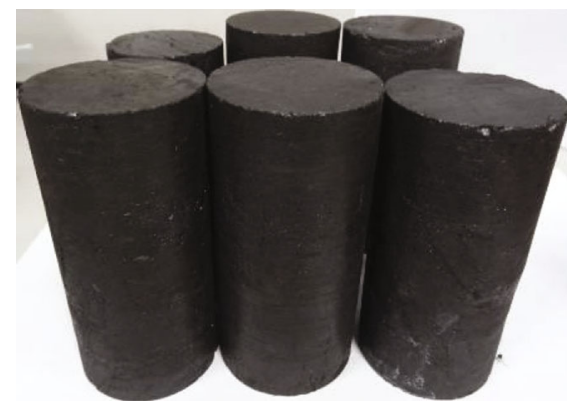

(b) Coal seam specimen

Figure 1: The machining test specimens.

great influence of coal cleats and nature fractures on the propagation paths of hydraulic fractures. Papadopoulos et al. [20] further used hydraulic samples instead of natural rock samples to carry out hydraulic fracturing simulation experiments and analyzed the multicrack expansion process and its interaction. Shang et al. [21] proposed an asymmetric fracturing method based on the experimental results considering the size effects of overlying-reservoir-underlying in porous reservoirs. Zhou et al. [22] conducted hydraulic fracturing field tests and indicated that the cracked surface is always perpendicular to the minor principal stress directions whether the liquid can penetrate the rock. Hou et al. [23-25] made visual analysis of the initiation and propagation in reservoir rocks on the basis of previous hydraulic fracturing work in intact coal seams. In summary, a lot of research has been reported on the law of hydraulic fracturing crack propagation and permeability. However, the above research mainly carries out the hydraulic fracturing experiment under the condition of single lithology or homogeneous layers. There is less control analysis of rock mechanical properties of the coal seam roof and floor on hydraulic fracturing. The difference in mechanical properties of the coal seam, roof, and floor rocks is an important factor to control hydraulic fracturing of the coal seam. The difference in mechanical properties of the coal seam roof and floor will affect the distribution of the ground stress field in the coal seam and directly determines the hydraulic fracturing effect of the coal seam. Therefore, this paper carried out the laboratory test of true triaxial hydraulic fracturing of the coal seam, and the combined model of "roof-coal seam-floor" is used to simulate the real strata conditions of the coal mine. The control effect of rock mechanics properties of the coal seam and its roof and floor on hydraulic fracturing fracture propagation is further analyzed. The research results have great significance for studying the extension mechanism and species distribution of the cracks.

\section{Basic Mechanical Property Test of Raw Coal and Roof-Floor}

The coal samples of hydraulic fracturing were drilled and collected from the M6-3 coal seam of the Tucheng Coal
Mine in southwest of China. The M6-3 coal seam is a black semidark-type coal, which has a metallic luster, is hard, and contains yellow iron nodules. The rock samples were from the roof and floor of the M6-3. The roof of M6-3 is composed of mudstone and sandy mudstone. The floor of M6-3 is composed of clay rock, mudstone, and sandy mudstone. All samples were processed into the standard specimens of $\varphi 50 \times 100 \mathrm{~mm}$ (Figure 1).

The mechanical parameters, elastic modulus $E$, and Poisson's ratio $\mu$ of all specimens were gained by the uniaxial compression tests. And the tensile strengths were tested by the Brazilian disc splitting experiments. The mechanical parameters of the coal, roof, and floor are shown in Table 1.

\section{Selection of Equivalent Materials for Coal Seam and Roof-Floor}

The specimen with the size of $600 \times 600 \times 500 \mathrm{~mm}$ $(L \times W \times H)$ is made by pour-shaping. The similar materials for preparing the coal seam and its roof and floor have similar mechanical characteristics with the coal seam and its roof and floor, such as failure characteristics, compressive strength, and tensile strength. The coal seam is prepared with pulverized coal, sand, and cement, while the roof and floor are prepared with sand, gypsum, and cement. According to the existing achievements about the ratio of model materials [26, 27], for the similar material ratio test scheme of the following five coal briquettes, six groups of the roof and floor were preliminarily determined, and three specimens were made in each group [28]. The prepared specimens were cured for 7 days, and the conventional mechanical properties were tested on the material testing machine [29-31]. The test results are shown in Tables 2 and 3.

According to the experimental results, different ratios of pulverized coal, sand, gypsum, and cement result in different compressive strengths and tensile strengths of specimens, while the dosage of cementing agent has great influence on the material strength. Based on the ratio of similitude between the ground stress of the coal seam and the loading stress of the experimental model, the Group B scheme is determined for the coal seam, the Group $\mathrm{C}$ scheme for the roof, and the Group E scheme for the floor to the production of similar materials. 
TABLE 1: Mechanical parameters of coal rock and roof-floor.

\begin{tabular}{|c|c|c|c|c|c|c|}
\hline \multirow[t]{2}{*}{ Rock formation } & \multicolumn{2}{|c|}{$\begin{array}{l}\text { The compressive strength } \\
\qquad \sigma_{\mathrm{c}}(\mathrm{MPa})\end{array}$} & \multicolumn{2}{|c|}{$\begin{array}{c}\text { Modulus of elasticity } \\
E(\mathrm{MPa})\end{array}$} & \multicolumn{2}{|c|}{$\begin{array}{c}\text { Tensile strength } \\
\sigma_{\mathrm{t}}(\mathrm{MPa})\end{array}$} \\
\hline & Sample & The average & Sample & The average & Sample & The average \\
\hline \multirow{3}{*}{ Coal } & 6.24 & & 1.186 & & 0.94 & \\
\hline & 6.49 & 6.47 & 1.307 & 1.195 & 1.21 & 1.09 \\
\hline & 6.68 & & 1.092 & & 1.13 & \\
\hline \multirow{3}{*}{ Roof } & 15.58 & & 2.661 & & 2.92 & \\
\hline & 16.52 & 15.95 & 2.562 & 2.636 & 3.283 & 3.22 \\
\hline & 15.76 & & 2.684 & & 3.458 & \\
\hline \multirow{3}{*}{ Floor } & 18.76 & & 2.947 & & 4.011 & \\
\hline & 19.13 & 18.91 & 2.984 & 2.942 & 3.507 & 3.58 \\
\hline & 18.85 & & 2.895 & & 3.224 & \\
\hline
\end{tabular}

TABLE 2: Mechanical parameters of coal briquette.

\begin{tabular}{|c|c|c|c|c|c|c|}
\hline \multirow[t]{2}{*}{ The ratio of solution } & \multicolumn{2}{|c|}{$\begin{array}{l}\text { The compressive } \\
\text { strength } \sigma_{\mathrm{c}}(\mathrm{MPa})\end{array}$} & \multicolumn{2}{|c|}{$\begin{array}{c}\text { Modulus of elasticity } \\
\text { E (MPa) }\end{array}$} & \multicolumn{2}{|c|}{$\begin{array}{c}\text { Tensile strength } \\
\sigma_{t}(\mathrm{MPa})\end{array}$} \\
\hline & Sample & The average & Sample & The average & Sample & The average \\
\hline \multirow{4}{*}{ Group A: pulverized coal: gypsum : cement $=1: 1: 1$} & 2.7828 & & 0.5537 & & 0.3219 & \\
\hline & 2.3263 & 2.4591 & 0.8204 & 0.5687 & 0.2968 & 0.3538 \\
\hline & 2.2681 & & 0.3321 & & 0.4426 & \\
\hline & 1.2318 & & 0.4617 & & 0.2018 & \\
\hline \multirow[t]{3}{*}{ Group B: pulverized coal: gypsum : cement $=5: 1: 3$} & 1.0377 & 1.2405 & 0.4138 & 0.4279 & 0.2243 & 0.2086 \\
\hline & 1.4521 & & 0.4082 & & 0.1996 & \\
\hline & 3.5214 & & 0.4862 & & 0.4251 & \\
\hline \multirow[t]{3}{*}{ Group C: pulverized coal: gypsum : cement $=3: 1: 3$} & 3.2367 & 3.5091 & 0.7124 & 0.6201 & 0.2784 & 0.4356 \\
\hline & 3.7693 & & 0.6618 & & 0.6032 & \\
\hline & 4.0213 & & 0.8032 & & 0.5021 & \\
\hline \multirow[t]{3}{*}{ Group D: pulverized coal: gypsum : cement $=2: 2: 1$} & 3.9827 & 4.1204 & 0.5683 & 0.8177 & 0.2218 & 0.5139 \\
\hline & 4.3571 & & 1.0817 & & 0.8179 & \\
\hline & 0.9437 & & 0.3041 & & 0.2217 & \\
\hline \multirow[t]{2}{*}{ Group E: pulverized coal : gypsum : cement $=5: 1: 2$} & 0.7824 & 0.8061 & 0.2854 & 0.2881 & 0.1126 & 0.1452 \\
\hline & 0.6921 & & 0.2747 & & 0.1013 & \\
\hline
\end{tabular}

\section{True Triaxial Hydraulic Fracturing Test and Discussion}

4.1. Preparation of Experimental Equipment and Specimen. The large-scale true triaxial and three-direction hydraulic fracturing test on different stress levels can be conducted with the independently developed large-scale simulation test rig and three-direction loading system for dynamic disasters of coal mine under multifield coupling. The experimental device is shown in Figure 2.

The experimental system consists of a test bench framework, hydraulic servo loading system, data acquisition system, and fracturing equipment. The test bench frame can be stored with large-scale specimens with the size of $1140 \times 600 \times 500 \mathrm{~mm}(L \times W \times H)$ and provide stable stress balance for the test. The hydraulic loading servo system consists of nine independent loading pressure heads, where each of the four hydraulic pressure heads at the horizontal direction ( $X$-direction) is applied with a maximum pressure of $1000 \mathrm{kN}$; one pressure head at the horizontal direction ( $Y$-direction) is applied with a maximum pressure of $2000 \mathrm{kN}$; each of the four pressure heads at the vertical direction ( $Z$-direction) is applied with a maximum pressure of $1000 \mathrm{kN}$; and each pressure head is independently controlled by computer software and a servo hydraulic pump. The data acquisition system is equipped with a special electrical control cabinet and connected to the computer with a multichannel data line through the cabinet, and then, the data are collected automatically by computer software. The fracturing equipment consists of a pressure pump, high-pressure pipeline, and fracturing pipe. The pressure pump can provide a maximum of $25 \mathrm{MPa}$ injection pressure, and the water tank with a volume of $5 \mathrm{~L}$ can accommodate the required injection water of the pump. During the hydraulic fracturing test, the 
TABLE 3: Mechanical parameters of similar materials for coal seam roof and floor.

\begin{tabular}{|c|c|c|c|c|c|c|}
\hline \multirow[t]{2}{*}{ The ratio of solution } & \multicolumn{2}{|c|}{$\begin{array}{l}\text { The compressive strength } \\
\sigma_{\mathrm{c}}(\mathrm{MPa})\end{array}$} & \multicolumn{2}{|c|}{$\begin{array}{c}\text { Modulus of elasticity } \\
\text { E (MPa) }\end{array}$} & \multicolumn{2}{|c|}{$\begin{array}{c}\text { Tensile strength } \\
\sigma_{\mathrm{t}}(\mathrm{MPa})\end{array}$} \\
\hline & Sample & The average & Sample & The average & Sample & The average \\
\hline \multirow{3}{*}{ Group A: sand: gypsum : cement $=1: 1: 1$} & 3.7032 & & 2.1884 & & 0.4853 & \\
\hline & 4.0124 & 3.9776 & 1.8621 & 2.0577 & 0.6027 & 0.4590 \\
\hline & 4.2171 & & 2.1226 & & 0.2891 & \\
\hline \multirow{3}{*}{ Group B: sand : gypsum : cement $=5: 1: 3$} & 2.1027 & & 2.0639 & & 0.3832 & \\
\hline & 1.9683 & 2.1465 & 1.8547 & 1.9401 & 0.1649 & 0.3868 \\
\hline & 2.3685 & & 1.9016 & & 0.6124 & \\
\hline \multirow{3}{*}{ Group C: sand: gypsum : cement $=4: 1: 5$} & 3.1984 & & 2.2278 & & 0.8084 & \\
\hline & 3.0861 & 3.0597 & 1.9419 & 2.1210 & 0.6431 & 0.6167 \\
\hline & 2.8947 & & 2.1934 & & 0.3986 & \\
\hline \multirow{3}{*}{ Group D: sand: gypsum : cement $=4: 2: 5$} & 4.2371 & & 2.6893 & & 0.5311 & \\
\hline & 3.8935 & 4.1549 & 2.7231 & 2.7184 & 0.4893 & 0.5105 \\
\hline & 4.3341 & & 2.7429 & & 0.5112 & \\
\hline \multirow{3}{*}{ Group E: sand: gypsum : cement $=4: 1: 6$} & 3.5975 & & 2.4512 & & 0.9513 & \\
\hline & 3.7892 & 3.6251 & 2.5297 & 2.3878 & 0.7704 & 0.6852 \\
\hline & 3.4887 & & 2.1824 & & 0.3339 & \\
\hline \multirow{3}{*}{ Group F: sand: gypsum : cement $=4: 2: 3$} & 2.6231 & & 2.6015 & & 0.4152 & \\
\hline & 2.3093 & 2.5790 & 2.5974 & 2.6124 & 0.4371 & 0.4145 \\
\hline & 2.8047 & & 2.6384 & & 0.3912 & \\
\hline
\end{tabular}

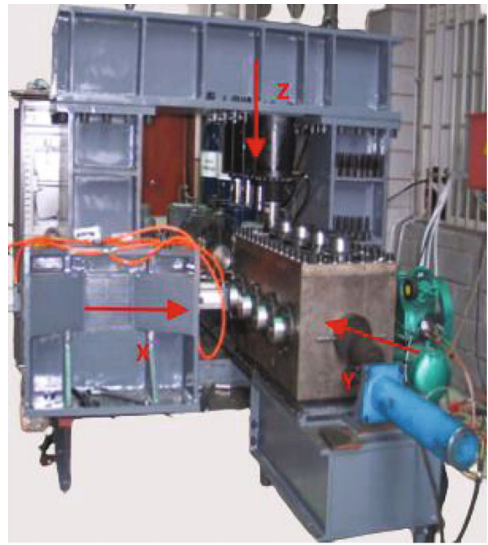

(a)

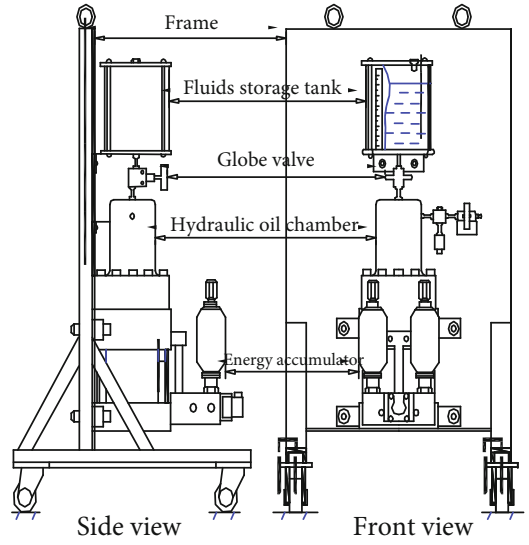

(b)

FIgURE 2: The large analog test system of multifield coupling mining dynamic disaster.

parameters, such as the injection pressure of the pump and the loading pressure, are collected and stored by computer software that is connected via data cable.

It is relatively difficult to process large bulky natural coal rock; therefore, this paper selected the coal seam and its roof and floor as test objects and then conducted the true triaxial hydraulic fracturing simulation test by simulating the coal seam and its roof and floor with similar materials based on hydraulic fracturing of the underground coal seam. The specimen size is $600 \times 600 \times 500 \mathrm{~mm}(L \times W \times H)$, which is poured by the method "floor-coal seam-roof" stratification. As shown in Figure 2(a), the lower part of the specimen is the floor, the middle part is the coal seam, and the top part is the roof. The thickness is $125 \mathrm{~mm}$ for the floor and roof and $250 \mathrm{~mm}$ for the coal seam. The bare hole section of the fracturing pipe is controlled in the coal seam, as shown in Figure 2. Moreover, the seamless steel tube with an external diameter of $16 \mathrm{~mm}$, inner diameter of $8 \mathrm{~mm}$, and length of $130 \mathrm{~mm}$ is preburied at about $10-20 \mathrm{~mm}$ of the top coal seam during pouring of the specimen; the bottom steel tube with $\Phi 6 \mathrm{~mm}$ steel bar is used as the drilling segment for simulation and the bottom of the steel bar is $10 \mathrm{~mm}$ away from the bottom coal seam, as shown in Figure 2(b). The naked eyelet section is formed when the steel bar is pulled out after shaping of the specimen and then used as the initial part to simulate drilling and fracturing in the coal seam.

The strength of the specimen can reach about $70 \%$ after shaping and curing for 7 days [32]. The injection water 


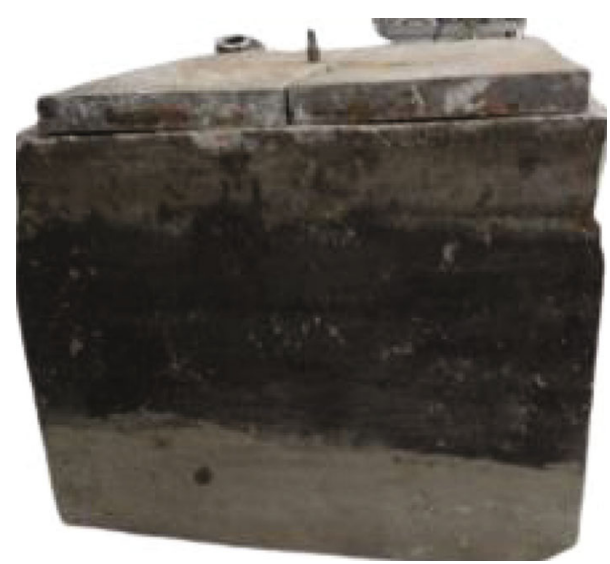

(a) Molding specimen

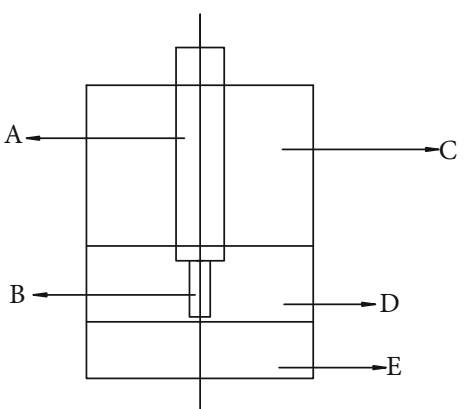

(b) Similar drilling: (A) fracturing tube, (B) open hole section, (C) roof, (D) coal seam, and (E) floor

FIGURE 3: Similar material molding specimens.

TABLe 4: Test loading scheme.

\begin{tabular}{lcccc}
\hline Scheme & $\sigma_{1}(\mathrm{MPa})$ & $\sigma_{2}(\mathrm{MPa})$ & $\sigma_{3}(\mathrm{MPa})$ & $\sigma_{3} / \sigma_{1}$ \\
\hline 1 & 3.51 & 2.92 & 1.23 & 0.35 \\
2 & 3.51 & 2.92 & 1.66 & 0.47 \\
3 & 3.51 & 2.92 & 2.28 & 0.65 \\
\hline
\end{tabular}

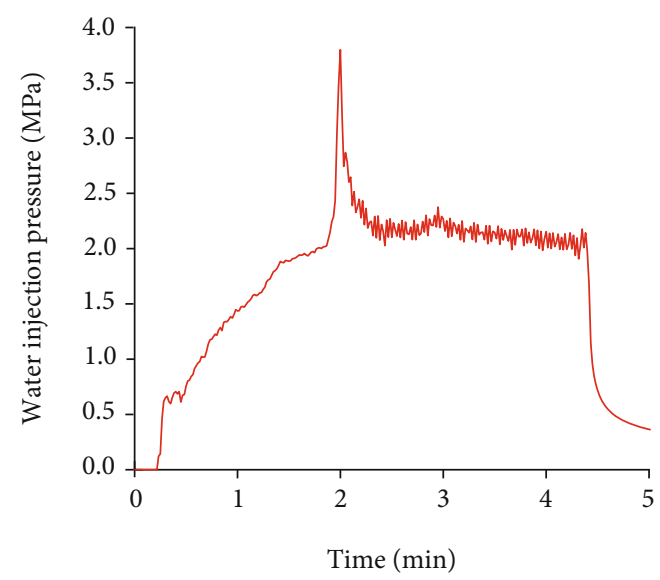

FIGURE 4: The pressure-time curve of the water injection of scheme 1.

displacement of the pump is $70 \mathrm{~L} / \mathrm{h}$, and the injection pressure of the pump can reach up to $25 \mathrm{MPa}$. The fracturing pipe is preburied in the coal seam and connected with the fracturing water pump via a high-pressure duct. During the fracturing test, the water tank is added with red ink and red pigment as tracers. With the expansion of water pressure cracks, the red pigment will be attached to the surface of the crack to indicate its final form. Figure 3 shows the specimen and experimental equipment.

4.2. Experiment for Expansion Rules of Crack with Variable Confining Pressure on Coal Seam. During the hydraulic fracturing in the coal seam, the ground stress is the main influencing factor of the extension of the crack. In order to study influences of the difference between the two horizontal principal stresses on the extension direction of the fractures, the fracturing test is conducted for variation of specific value between the horizontal minimum and maximum principal stress to obtain the influencing rules of the horizontal principal stress on the direction of the hydraulic fracture.

In the experiment, the materials of simulating the coal seam and its roof and floor in the specimen are constant, the horizontal maximum principal stress $\sigma_{1}$ and intermediate principal stress (vertical stress) $\sigma_{2}$ remain constant, but the horizontal minimum principal stress $\sigma_{3}$ is changed. The loading scheme is shown in Table 4.

4.3. Scheme 1: Experimental Process, Analysis, and Discussion. Figure 4 shows the variation curve of water injection pressure with time. With the gradual increase of the water injection rate, the pressure at the hole bottom increases slowly and the shutoff pressure starts at $20 \mathrm{~s}$. The water pressure is $0.61 \mathrm{MPa}$ at $43 \mathrm{~s}$, and then, the injection pressure increases rapidly. The water pressure reaches the peak value of $3.67 \mathrm{MPa}$ at $58 \mathrm{~s}$. And the borehole wall ruptures, resulting in initial cracks. The water pressure decreases rapidly due to the increase of liquid storage space and then increases rapidly with the injection water of the pump. As a result, the crack extends continuously until the surface of the specimen cracks and the pressure water is spilled. Then, the pump stops, and the fracturing test is ended.

Figure 5(a) shows the extension direction of the hydraulic fracture when the ratio of horizontal principal stresses is $\sigma_{3} / \sigma_{1}=0.35$. It can be seen that the included angle between the extension direction of the hydraulic fracture and the direction of the maximum principal stress is about $42^{\circ}$, and the crack extends along this direction and extends along the direction perpendicular to the horizontal minimum principal stress. Figure $5(\mathrm{~b})$ shows the morphology of the hydraulic fracture from the profile of the specimen after splitting. It can be seen that the hydraulic fracture is generally elliptical and distributed asymmetrically. The reason is that once the crack appears on one side and extends, the crack may be stopped on the dense or high-stress area on 


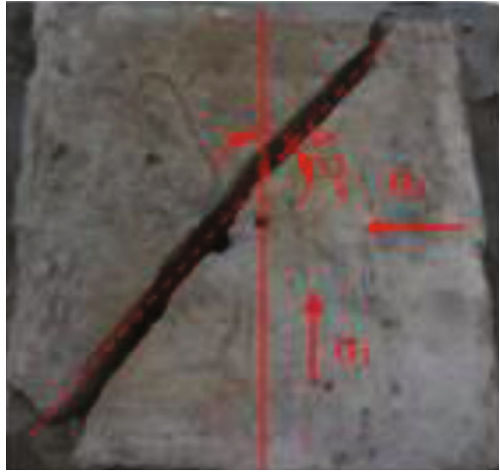

(a) Hydraulic fracturing

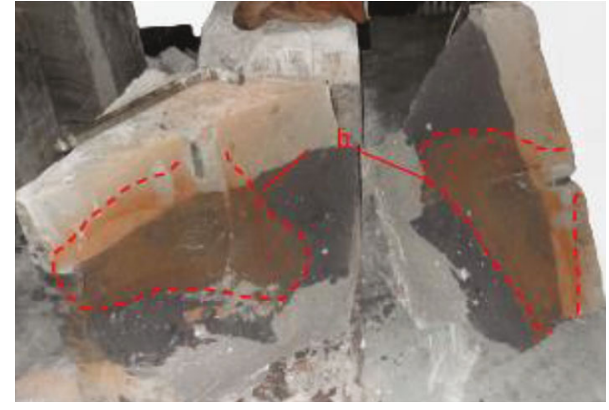

(b) Fracturing morphology

Figure 5: The hydraulic fracturing morphology of scheme 1.

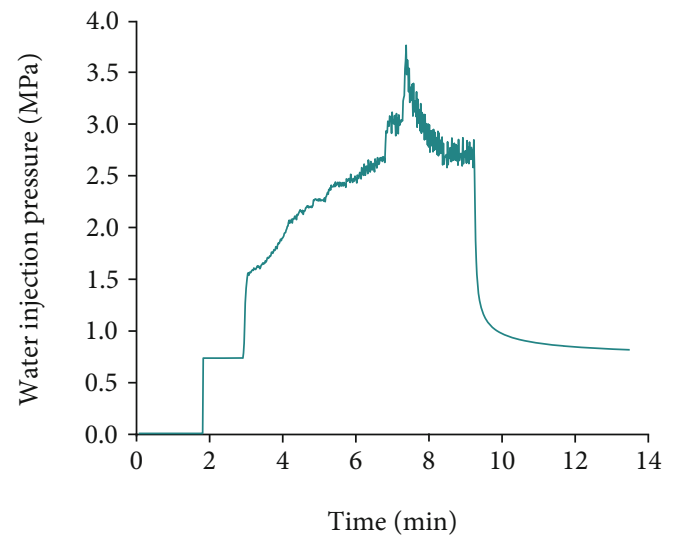

FIGURE 6: The pressure-time curve of the water injection of scheme 2.

the other side, resulting in the asymmetric distribution of the extension on both sides of the crack.

4.4. Scheme 2: Experimental Process, Analysis, and Discussion. Figure 6 shows the variation curve of water injection pressure with time. The water injection rate increases gradually, and the injection pressure starts to increase after the opening of the fracturing water pump. The water pressure reaches $1.53 \mathrm{MPa}$ at $2 \mathrm{~min}$. After that, the injection pressure increases approximately linearly, and the water pressure reaches $2.6 \mathrm{MPa}$ at $5.4 \mathrm{~min}$. Besides, the water pressure increases continuously under the shutoff pressure at the borehole bottom and then reaches the peak of $3.46 \mathrm{MPa}$ at $6.3 \mathrm{~min}$. The borehole wall is fractured and the pump pressure decreased. Later, the crack begins to extend during continuous injection of high-pressure water until the pressure water is spilled on the surface of the specimen; then, the pump stops, and the fracturing test is ended.

Figure 7(a) shows the extension direction of the hydraulic fracture when the ratio of horizontal principal stresses is $\sigma_{3} / \sigma_{1}=0.47$. It can be seen that the included angle between the extension direction of the hydraulic fracture and the direction of the horizontal maximum principal stress $\sigma_{1}$ is about $39^{\circ}$, and the crack extends along this direction and extends along the direction perpendicular to the horizontal minimum principal stress. Figure 7 (b) shows the morphology of the hydraulic fracture from the profile of the speci- men. It can be seen that the crack is generally elliptical and distributed asymmetrically for both sides centered on the drilling. The hydraulic fracture basically extends in the coal seam, and some segments of the crack passes through the roof. The deep red color can be seen around the fracturing pipe with significant hydraulic traces due to the microcrack between the material and the fracturing pipe resulting from incomplete hole sealing. Therefore, hole sealing is a crucial factor to the success of hydraulic fracturing.

4.5. Scheme 3: Experimental Process, Analysis, and Discussion. Figure 8 shows the variation curve of water injection pressure with time. After the test, with the increase of the injection water of the pump, the water pressure basically remains zero at $45 \mathrm{~s}$. With the formation of shutoff pressure while the hole bottom is filled with pressure water, the water pressure increases rapidly and reaches $2.1 \mathrm{MPa}$ at $2 \mathrm{~min}$ and then reaches the peak value of $3.80 \mathrm{MPa}$, resulting in a crack at the naked eyelet segment. The liquid storage space further increases, and the pressure water rapidly declines. After that, with continuous injection of the pressure water by the pump, the high-pressure water results in the continuous extension of the crack, forming a crack surface and finally reaching the surface of the specimen. As a result, the pressure water spills out and the pump stops, and then, the fracturing test is ended.

Figure 9(a) shows the extension direction of the hydraulic fracture when the ratio of horizontal principal stresses is $\sigma_{3} / \sigma_{1}=0.65$. It can be seen that the hydraulic fracture is basically perpendicular to the horizontal minimum principal stress, and the included angle between the extension direction of the fracture and the direction of the horizontal maximum principal stress $\sigma_{1}$ is within $6^{\circ}$. Figures $9(\mathrm{~b})$ and $9(\mathrm{c})$ show the form of the hydraulic fracture from the profile of the specimen. It can be seen that the crack is generally elliptical and distributed symmetrically centered on the drilling. The hydraulic fracture basically extends in the coal seam, and some segments of the crack partially penetrate the roof. The reason may be that some high-pressure water penetrates the roof near the borehole due to the loose sealing.

4.6. Experiment for Extension Rules of Crack with Equivalent Confining Pressure on Coal Seam. In order to further study 


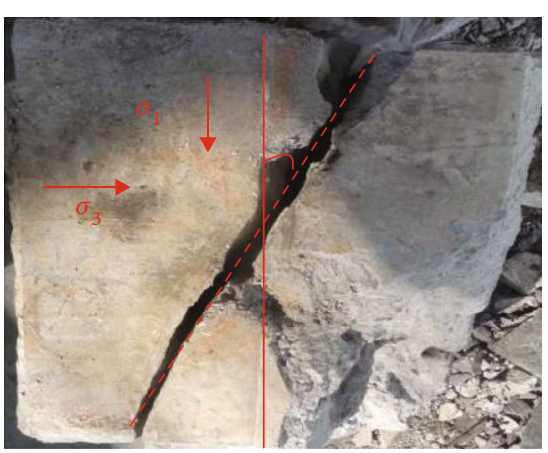

(a) The direction of hydraulic fracture extension

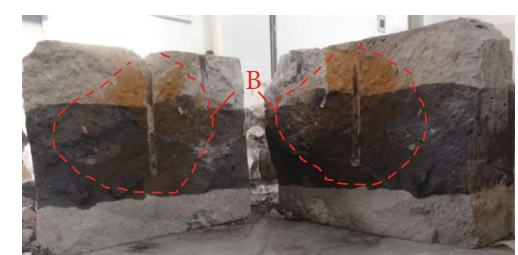

(b) Morphology after hydraulic fracture expansion

Figure 7: The hydraulic fracturing morphology of scheme 2.

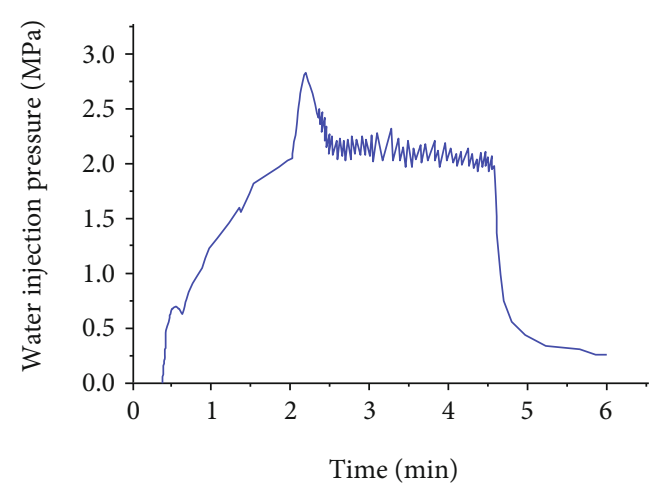

FIGURE 8: The pressure-time curve of the water injection of scheme 3.

the extension laws of the crack under the effect of the stress field in the coal seam, the hydraulic fracturing test is conducted under the condition of an equivalent confining pressure. The condition of the stress field in the simulation site is set to $\sigma_{1}=\sigma_{3}<\sigma_{2}$, and the main stresses at three directions are $\sigma_{1}=\sigma_{3}=2.0 \mathrm{MPa}$ and $\sigma_{2}=2.92 \mathrm{MPa}$.

Figure 10 shows the variation curve of the water injection pressure with time. The pump pressure reaches $0.63 \mathrm{MPa}$ at $57 \mathrm{~s}$ and peak point of $3.16 \mathrm{MPa}$ at $1.6 \mathrm{~min}$. The borehole wall begins to get damaged, new cracks are generated, and the new chasm cracks make the water pressure drop rapidly. Since then, with the increase of the pump injection pressure, the hydraulic fracture extends continuously until the surface of the specimen cracks and pressure water spills out. The pump stops, and then, the fracturing test is ended.

Figure 11(a) shows the extension direction of the hydraulic fracture under the condition of equivalent confining pressure. It can be seen that the crack basically extends along the direction perpendicular to the $\sigma_{1}$ and extends along the $\sigma_{3}$ direction, and the extension direction of the crack is consistent with the $\sigma_{3}$ direction. Under the condition of equivalent confining pressure, the hydraulic fracture extends randomly at the horizontal direction under the effect of the ground stress and water pressure coupling if the material is homogeneous. The hydraulic fracture will extend along the dominant surface once the crack is split, when extension direction is mainly affected by defects, weak plane, and fissure of the material itself. Figures 11(b) and 11(c) show the morphology of the hydraulic fracture from the profile of the specimen. It can be seen that the crack is generally elliptical and distributed asymmetrically centered on the drilling and basically extended from one side. The hydraulic fracture basically extends in the coal seam, and the height of the cracks changes and partially passes through the roof and floor.

\section{Comparison and Analysis of Test Results}

5.1. Influence of Stress Ratio on Crack Propagation Angle. Figures 12 and 13 show the pressure-time curves and fracture propagation diagrammatic drawing under different maximum and minimum horizontal principal stress ratios. It can be seen that deflection occurs at the extension direction. As the ratio of the minimum and the maximum horizontal principal stress increases from 0.35 to 0.65 , the angle of hydraulic fracture propagation changes from $36^{\circ}$ to $6^{\circ}$. The angle between the direction of the hydraulic fracture propagation and the direction of the maximum horizontal principal stress decreases gradually. The results show that when shear failure or tensile failure occurs in the coal seam, failure occurs along the bedding. With the change of the horizontal stress ratio, the pressure required for failure remains relatively constant, which is mainly due to the dominant vertical ground stress, and the horizontal stress difference has little effect on the bedding plane. As the ratio continues to increase, the water pressure required for failure along the corresponding dip joints and strike joints decreases linearly. Overall, the water pressure required for different failure modes decreases linearly with the increase of the horizontal stress ratio. For the same plane or joint layer, the water pressure required for shear failure is also greater than that required for tensile failure. This may be due to the fact that the sample is made by pouring, which is a heterogeneous material. At the same time, limited by the experimental conditions, the confining stress is too small, thus causing the change of crack propagation angle. The fracturing pressure of the crack is closely related to the horizontal minimum principal stress. When the specific value of the horizontal principal stress under the confining pressure increases, the horizontal minimum principal stress and related fracturing pressure increase, but the intermediate principal stress (i.e., burial depth) has little effect on the 


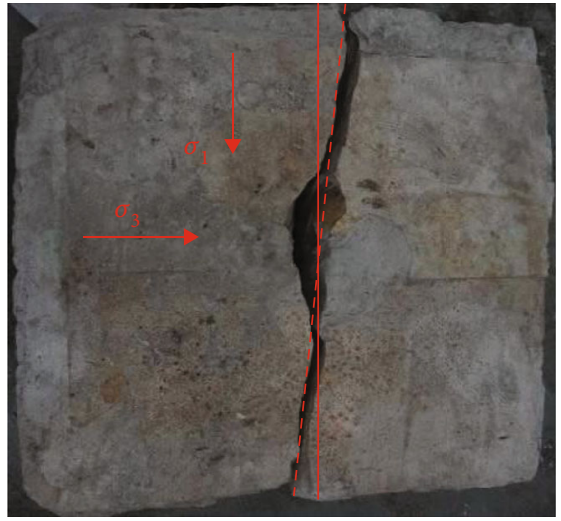

(a) Hydraulic fracturing

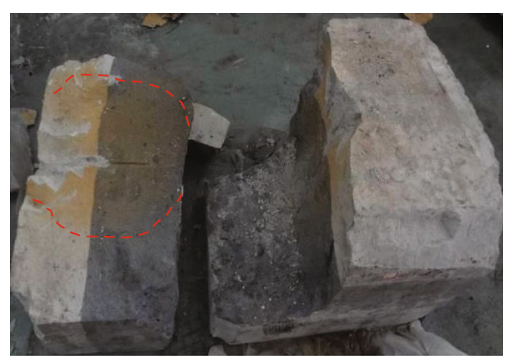

(b) The specimen after fracturing

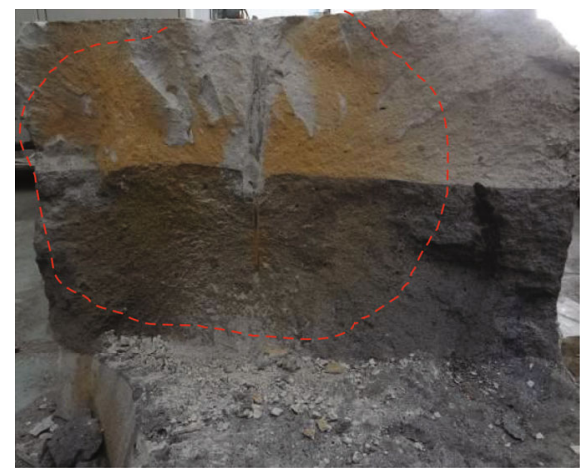

(c) Fracturing morphology

FIgURE 9: The hydraulic fracturing morphology of scheme 3.

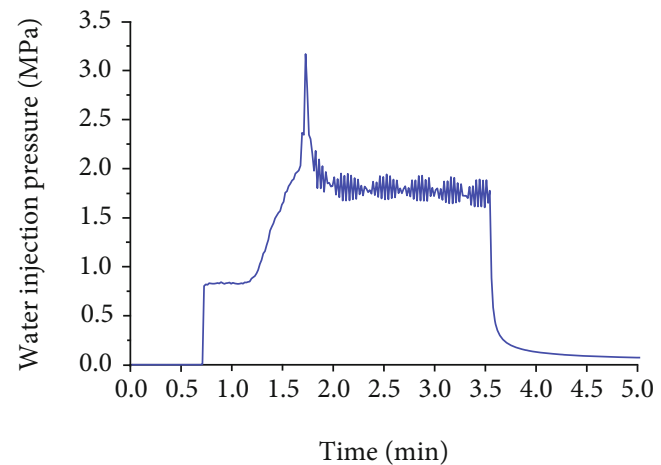

Figure 10: The pressure-time curve of the water injection of equivalent confining pressure.

fracturing pressure [33]. Therefore, the smaller the specific value between the horizontal minimum and the maximum principal pressure under the confining pressure is, the larger the included angle between the extension direction of crack and the direction of horizontal maximum principal stress will be, and the easier the development of the crack will be. In conclusion, the extension direction of the hydraulic fracture is related to two horizontal principal stresses.

\section{Turning Test for Hydraulic Fracture on the Coal Seam}

Due to the effect of ground stress, the principal hydraulic fracture shows certain deflection during extension. However, there are no reliable instruments available to observe crack extension and steering in the field; hence, a thorough understanding of the law of crack extension is not very clear. Therefore, it is necessary to study the extension law of the crack due to hydraulic fracturing by laboratory tests. In order to study the influences of the changed ground stress in the coal seam on extension of the hydraulic fracture, the test scheme is determined as below, in which the three direction principal stresses are $\sigma_{1}=3.51 \mathrm{MPa}, \sigma_{2}=2.92 \mathrm{MPa}$, and $\sigma_{3}=1.66 \mathrm{MPa}$. There are two bearing plates at the direction of the horizontal maximum principal stress, as shown in Figure 14. During the test, when the experimental equip- ment is loaded to define the value of three direction stresses, the fracturing operation is conducted, and one bearing plate at the $\sigma_{1}$ direction under the confining pressure is unloaded completely and then loaded to the defined value to study the extension law of the hydraulic fracture.

Figure 15 shows the variation curve of the injection pressure of the pump with time during the loading process. The injection pressure of the pump starts to increase after $30 \mathrm{~s}$, and the water pressure is $0.8 \mathrm{MPa}$ at $1.1 \mathrm{~min}$. After that, under the effect of the shutoff pressure, the water pressure rapidly reaches the first peak stress of $2.6 \mathrm{MPa}$, and new cracks were generated when the hole wall was damaged. The water pressure filled the cracks and reduced the pressure. The shutoff pressure increases, and the hydraulic fracture extends with continuous water supply under pump pressure. When the confining pressure decreases suddenly, the pump pressure decreases continuously. Because the confining pressure decreases, the hydraulic cracks in the specimen only need to overcome the tensile or shear strength of the coal seam. As a result, the injection pressure declines. The hydraulic fracture will extend along the area with smaller energy demands, i.e., the area without confining pressure, at this time, when the hydraulic fracture turns and extends to the direction with declined confining pressure. However, the water pressure required for extension of the hydraulic fracture gradually increases with the confining pressure. The water pressure reaches the second peak stress of $2.6 \mathrm{MPa}$ under the effect of the shutoff pressure and then declines due to the new crack filled with pressure water. Then, the water pressure cracks along the direction of small ground stress cracking, with extension, until the surface of the specimen, the pressure water spills out, and the pump stops; then, the hydraulic test is ended.

Figure 16 shows the form of hydraulic fracture morphology gradually cutting open the specimen after the test. A significant turn can be seen from the red traces of the hydraulic fracture, and the crack surface is curved with a degree larger than $90^{\circ}$. The hydraulic fracture generally expands in the coal seam. Due to the existence of microcracks in the sealing hole, some cracks pass through the roof, and the cracks are basically elliptical. According to the analysis for turning of 


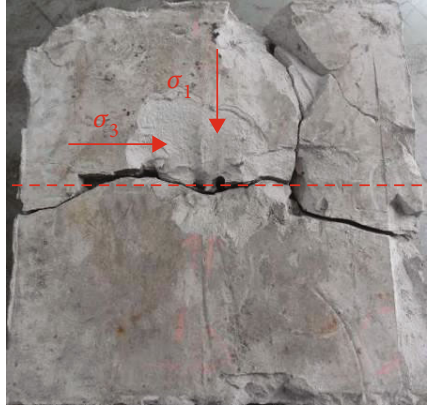

(a) The direction of hydraulic fracture extension

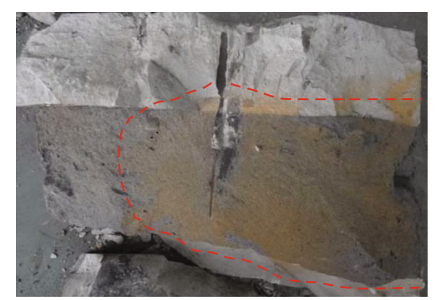

(c) Water pressure fracture surface

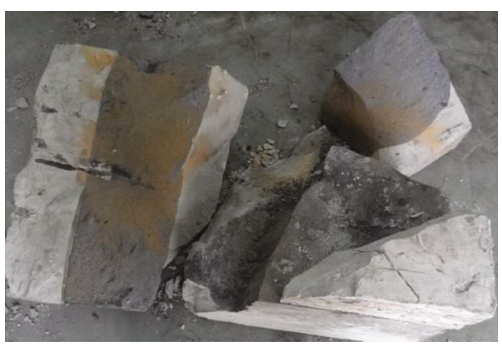

(b) The shape of the specimen after opening

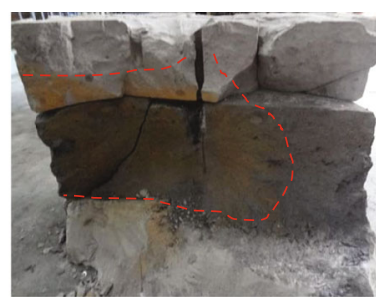

Figure 11: The hydraulic fracturing morphology of equivalent confining pressure.

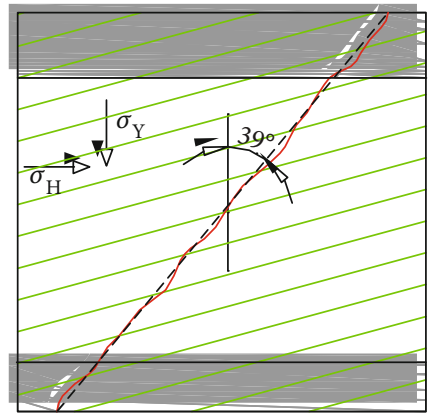

(a) Maximum and minimum horizontal principal stress ratios: 0.35

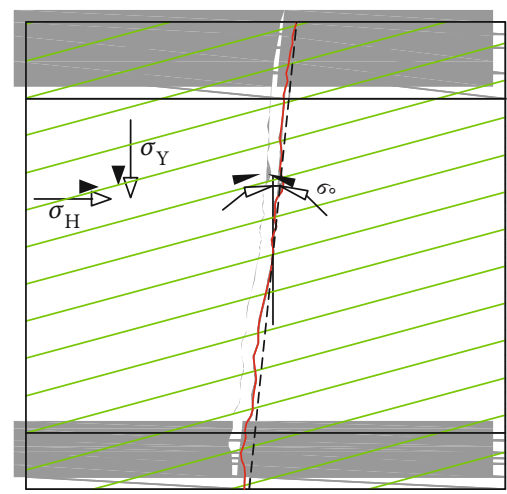

(c) Maximum and minimum horizontal principal stress ratios: 0.65

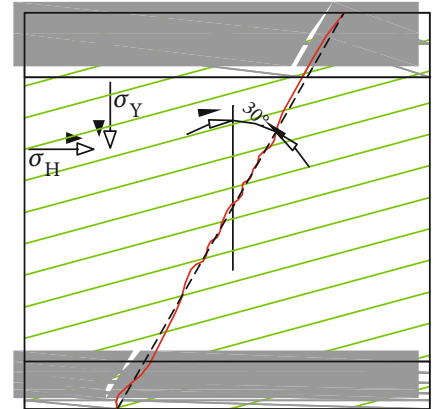

(b) Maximum and minimum horizontal principal stress ratios: 0.47

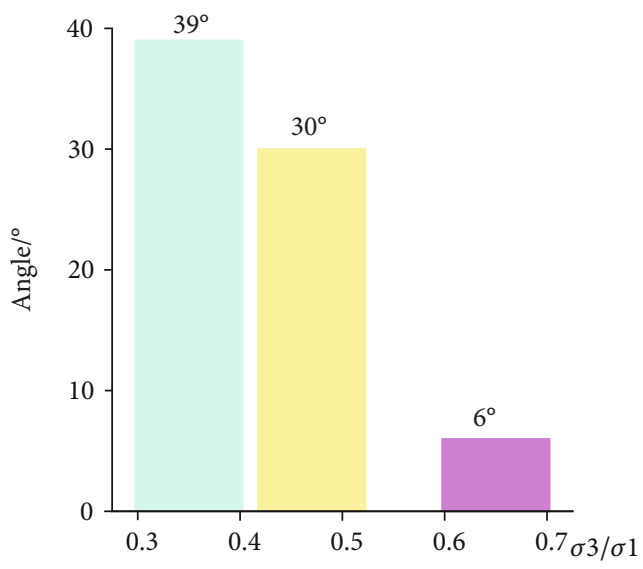

Maximum and minimum horizontal stress ratios

(d) Expansion angle change

FIGURE 12: Fracture propagation graphs produced under the condition of different maximum and minimum horizontal principal stress ratios.

hydraulic fracture, the crack extends along surface 1 initially under the triaxial stress. During the extension process, the principal stress perpendicular to the direction of surface 2 is unloaded suddenly and tends to the state without confining pressure, which leads to rapid decrease of fracturing pressure of the coal seam. The pressure of the coal seam 


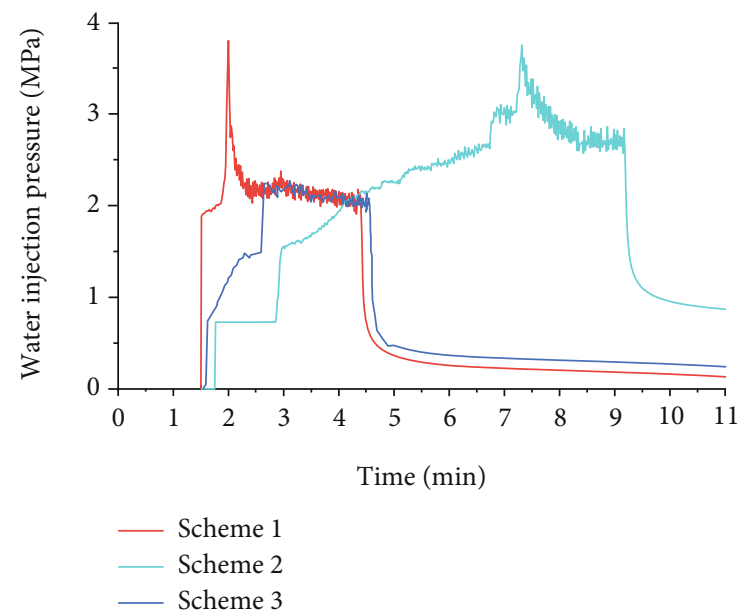

FIGURE 13: Pressure-time curves of different maximum and minimum horizontal principal stress ratios.

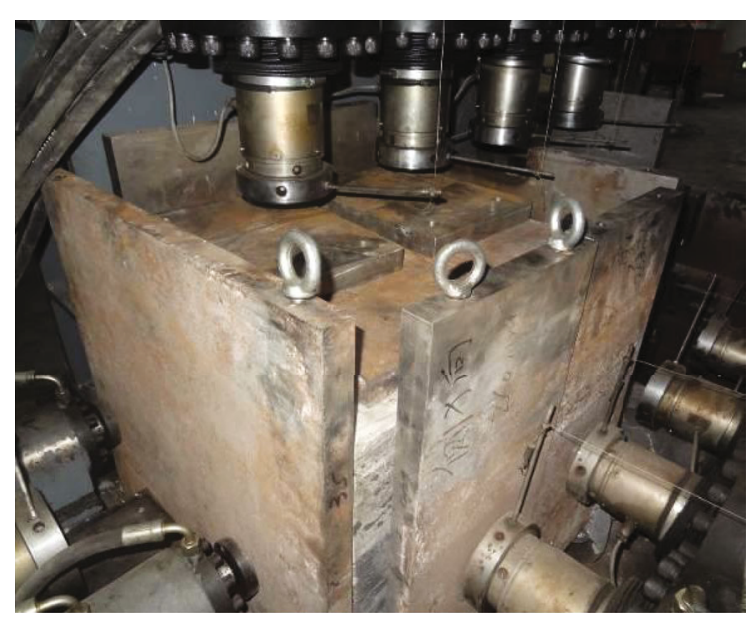

Figure 14: The horizontal loading way bearing plate.

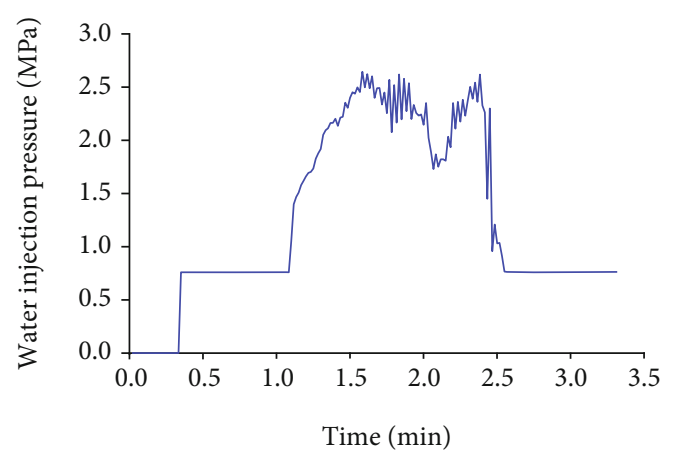

Figure 15: The pressure-time curve of the water injection of turning test.

fractured by high-pressure water decreases, the crack rapidly turns to surface 2 without the confining pressure, and then, the crack extension in surface 1 stops. Subsequently, the pressure perpendicular to the direction of surface 2 rapidly increases to the maximum principal stress, while the crack on surface 2 stops under the effect of the horizontal maxi-

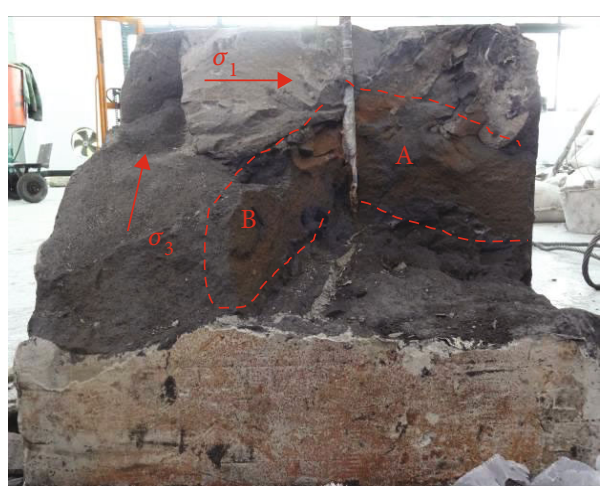

FIgURE 16: The hydraulic fracturing morphology of turning test: (A) surface 1 ; (B) surface 2 .

mum principal stress, and then, the hydraulic fracture again extends along surface 1 to the surface of the specimen, forming the crack running through the coal seam and turning crack surfaces which are almost perpendicular. Therefore, ground stress is the most important factor that influences the extension of the hydraulic fracture. The change of ground stress will cause the direction change of crack expansion, which is the decisive factor for the direction of crack extension.

\section{Conclusions}

(1) The extension direction of the hydraulic fracture is related to two horizontal principal stresses. With the increase of the ratio of the minimum and maximum horizontal principal stresses, the angle between the extension direction of the hydraulic fracture and the direction of the maximum horizontal principal stress decreases gradually. The fracturing pressure during crack extension is closely related to the horizontal minimum principal stress. When the ratio of the horizontal principal stress under the confining pressure increases, the corresponding fracture pressure also increases. But the intermediate principal stress that is the buried depth has little effect on the fracture pressure. Therefore, the smaller the confining pressure and the maximum horizontal principal stress ratio, the greater the angle between the fracture extension direction and the maximum horizontal principal stress direction, and the easier the fracture cracking

(2) Under the condition of constant confining stress, the hydraulic fracture extends randomly at the horizontal direction under the effect of ground stress and pressure coupling if the material is homogeneous. The hydraulic fracture will extend along the dominant surface once the crack is split, when the extension direction is mainly affected by defects, weak plane, and fissure of the material. The overall shape of the hydraulic fracture is elliptical and distributed asymmetrically centered on the drilling and is basically a unilateral extended suture. The hydraulic fracture generally extends in the coal seam, and some change of the crack height passes through the roof and floor 
(3) The hydraulic fracture steering test of the coal seam shows that the extension direction of the hydraulic fracture is mainly controlled by the ground stress, and when there is confining pressure, the crack usually extends along the direction of the maximum horizontal principal stress but turns to and extends along the direction perpendicular to the direction without confining pressure, forming the curved surface with a degree larger than $90^{\circ}$. The hydraulic fracture generally extends in the coal seam and presents an elliptical form. Besides, the extension, termination, and turning of the hydraulic fracture are mainly limited by the horizontal maximum principal stress. Therefore, ground stress is the most important factor that influences the extension of the hydraulic fracture. The change of ground stress will cause the direction change of crack extension being a decisive factor for the direction of the crack extension

\section{Data Availability}

The data used to support the findings of this study are included within the article.

\section{Conflicts of Interest}

The authors declare that they have no conflicts of interest.

\section{References}

[1] L. Yuan, N. Zhang, J. G. Kan, and Y. Wang, "The concept, model and reserve forecast of green coal resources in China," Xuzhou: China University of Mining and Technology, vol. 47, no. 1, pp. 1-8, 2018.

[2] S. N. Zhou, "Mechanism of gas flow in coal seam," Journal of China Coal Society, vol. 15, no. 1, pp. 15-24, 1990.

[3] Y. S. Kang, L. Z. Sun, B. Zhang, J. Y. Gu, and D. L. Mao, "Discussion on classification of coal bed reservoir permeability in China," Journal of China Coal Society, vol. 42, pp. 186-194, 2017.

[4] K. H. Ge, L. Yang, Y. H. Shen et al., "Experimental investigation of shale imbibition capacity and the factors influencing loss of hydraulic fracturing fluids," Petroleum Science, vol. 12, no. 4, pp. 636-650, 2015.

[5] J. Gu, S. Wang, C. Ma, P. Gan, and N. Tang, "Influence of drilling fluid components on shear strength at cement-aquifuge interface in coalbed methane wells," Acta Geologica Sinica (English Edition), vol. 91, no. 4, pp. 1511-1512, 2017.

[6] H. Chen, H. Qi, R. Long, and M. Zhang, "Research on 10-year tendency of China coal mine accidents and the characteristics of human factors," Safety Science, vol. 50, no. 4, pp. 745-750, 2012.

[7] G. Chen, "Analysis of coal and gas outburst induced rock burst accidents in Yangou coal mine," Safety in Coal Mines, vol. 44, no. 7, pp. 156-158, 2013.

[8] B. Gao, X. Mi, and R. Zhang, "Research status and prospect of compound dynamic disaster of deep mining in coal mine," Safety in Coal Mines, vol. 44, no. 11, pp. 175-178, 2013.

[9] I. Oraki Kohshou, R. Barati, M. C. Yorro et al., "Economic assessment and review of waterless fracturing technologies in shale resource development a case study," Journal of Earth Science, vol. 28, no. 5, pp. 933-948, 2017.

[10] Q. B. Meng, W. Qian, H. Pu, B. X. Huang, and C. K. Wang, "Experimental study on mechanical properties of damaged and fractured rock samples," Chinese Journal of Rock Mechanics and Engineering, vol. 39, no. 8, pp. 1534-1546, 2020.

[11] W. Cheng, G. S. Jiang, J. Y. Xie, Z. J. Wei, Z. D. Zhou, and X. D. $\mathrm{Li}$, "A simulation study comparing the Texas two-step and the multistage consecutive fracturing method," Petroleum Science, vol. 16, no. 5, pp. 1121-1133, 2019.

[12] M. K. Hubbert and D. G. Willis, "Mechanics of hydraulic fracturing," Trans Social Petroleum English AIME, vol. 210, no. 1, pp. 153-168, 1957.

[13] T. G. Fan, G. Q. Zhang, and J. B. Cui, "The impact of cleats on hydraulic fracture initiation and propagation in coal seams," Petroleum Science, vol. 11, no. 4, pp. 532-539, 2014.

[14] J. N. Dong, J. G. Yuan, X. Y. Wang et al., "Experimental study of multi-timescale crack blunting in hydraulic fracture," Petroleum Science, vol. 18, no. 1, pp. 234-244, 2021.

[15] C. L. Cipolla, N. R. Warpinski, M. J. Mayerhofer, E. P. P. Lolon, and M. C. C. Vincent, "The relationship between fracture complexity, reservoir properties, and fracture-treatment design," SPE Production \& Operations, vol. 25, no. 4, pp. 438-452, 2010.

[16] C. Wei, E. S. Zhu, Y. Li, S. G. Wang, Z. X. Dong, and W. B. Cai, "Experimental study and numerical simulation of inclined flaws and horizontal fissures propagation and coalescence process in rocks," Rock and Soil Mechanics, vol. 40, no. 11, pp. 4533-4542, 2019.

[17] H. W. Yang, Y. Zhao, X. H. Zhang et al., "Supercritical $\mathrm{CO}_{2}$ fracturing with different drilling depths in shale," Energy Sources, vol. 18, no. 3, pp. 1-20, 2019.

[18] S. Li, Y. F. Chen, Z. J. Li, and K. Zhang, "Applying a statistical method to streamflow reduction caused by underground mining for coal in the Kuye River basin," Basin Science China (Technological Sciences), vol. 59, no. 12, pp. 1911-1920, 2016.

[19] B. X. Huang, Q. Y. Cheng, and S. L. Chen, "Phenomenon of methane driven caused by hydraulic fracturing in methanebearing coal seams," International Journal of Mining Science and Technology, vol. 26, no. 5, pp. 919-927, 2016.

[20] J. M. Papadopoulos, V. M. Narendran, and M. P. Cleary, Laboratory simulation of hydraulic fracturing, Society of Petroleum Engineers Symposium Low Permeability, 1983.

[21] D. L. Shang, G. Z. Yin, Y. Zhao et al., "Local asymmetric fracturing to construct complex fracture network in tight porous reservoirs during subsurface coal mining: an experimental study," Journal of Natural Gas Science and Engineering, vol. 59, pp. 343-353, 2018.

[22] Z. Zhou, H. Yang, X. C. Wang, and Q. F. Zhang, "Fractured rock mass hydraulic fracturing under hydrodynamic and hydrostatic pressure joint action," Journal of Central South University, vol. 23, no. 10, pp. 2695-2704, 2016.

[23] P. Hou, X. Liang, F. Gao, J. B. Dong, J. He, and Y. Xue, "Quantitative visualization and characteristics of gas flow in $3 \mathrm{D}$ pore-fracture system of tight rock based on lattice Boltzmann simulation," Journal of Natural Gas Science and Engineering, vol. 89, no. 4, p. 103867, 2021.

[24] P. Hou, X. Liang, Y. Zhang, J. He, F. Gao, and J. Liu, “3D multiscale reconstruction of fractured shale and influence of fracture morphology on shale gas flow," Natural Resources Research, vol. 30, no. 3, pp. 2463-2481, 2021. 
[25] X. Liang, P. Hou, Y. Xue, X. J. Yang, F. Gao, and J. Liu, “A fractal perspective on fracture initiation and propagation of reservoir rocks under water and nitrogen fracturing," Fractals. Complex Geometry. Patterns and Scaling in nature and Society, vol. 29, p. 7, 2021.

[26] S. Q. Liu, S. X. Sang, Q. P. Zhu et al., "Triple medium physical model of post fracturing high-rank coal reservoir in southern Qinshui Basin,” Basin Journal of Earth Science, vol. 26, no. 3, pp. 407-415, 2015.

[27] Y. Zhao, S. G. Cao, D. L. Shang et al., "Crack propagation and crack direction changes during the hydraulic fracturing of coalbed," Computers and Geotechnics, vol. 111, pp. 229-242, 2019.

[28] S. C. Li, Q. Wang, H. T. Wang et al., "Model test study on surrounding rock deformation and failure mechanisms of deep roadways with thick top coal," Tunnelling and Underground Space Technology, vol. 47, pp. 52-63, 2015.

[29] Z. B. Cheng, L. H. Li, and Y. N. Zhang, "Laboratory investigation of the mechanical properties of coal-rock combined body," Bulletin of Engineering Geology and the Environment, vol. 79, no. 4, pp. 1947-1958, 2020.

[30] G. Z. Yin, D. L. Shang, M. H. Li et al., "Permeability evolution and mesoscopic cracking behaviors of liquid nitrogen cryogenic freeze fracturing in low permeable and heterogeneous coal," Powder Technology, vol. 325, pp. 234-246, 2018.

[31] H. Wu, D. Ma, A. J. S. Spearing, A. J. Spearing, and G. Zhao, "Fracture phenomena and mechanisms of brittle rock with different numbers of openings under uniaxial loading," Geomechanics and Engineering, vol. 25, no. 6, pp. 481-493, 2021.

[32] N. Cho, C. D. Martin, and D. C. Sego, "A clumped particle model for rock," International Journal of Rock Mechanics and Mining Sciences, vol. 44, no. 7, pp. 997-1010, 2007.

[33] P. Cao, T. Y. Liu, C. Pu, and H. Lin, "Crack propagation and coalescence of brittle rock-like specimens with pre- existing cracks in compression," Engineering Geology, vol. 187, no. 17, pp. 113-121, 2015. 